\title{
La balandra Isabel llegó esta tarde: Las metáforas del mar y la construcción de los roles de género en el cine venezolano de la primera mitad del siglo $\mathrm{XX}$
}

The Yacht Isabel Arrived This Afternoon: Sea Metaphors and the Construction of Gender Roles in the Venezuelan Cinema of the First Half of the $20^{\text {th }}$ Century

CAROLINA GUTIÉRREZ-RIVAS

CENTRAL MICHIGAN UNIVERSITY

Artículo recibido el / Article received: 2019-06-14

Artículo aceptado el / Article accepted: 2019-10-03

RESUMEN: El objetivo de este estudio es presentar un análisis lingüístico de las metáforas conceptuales relativas al mar (u otras masas de agua) para dilucidar su papel en la construcción de los roles tradicionales de género en la película $L a$ balandra Isabel llegó esta tarde. Se emplea la teoría de la metáfora conceptual de Lakoff y Johnson (1980), sobre todo observando las metáforas estructurales y ontológicas, así como las nociones de poder discursivo (van Dijk, 2004) e ideología (van Dijk, 2008). El análisis arroja que las metáforas estructurales y ontológicas en el filme retratan al hombre como el capitán, el protector y la víctima de la mujer. Por su parte, las metáforas con las que se representa a la mujer son las del mar, el navío y el naufragio. Se concluye que hay un proceso de retroalimentación en la difusión y perpetuación de las ideologías de los roles género. El concepto de «obediencia lingüística» (Komska, Moyd y Gramling, 2019) es de relevancia para explicar el comportamiento lingüístico de los personajes.

Palabras clave: balandra Isabel, cine venezolano, metáforas, poder discursivo, roles de género, obediencia lingüística.

ABSTRACT: The aim of this work is to develop a linguistic analysis focused on conceptual metaphors related to the sea (or other bodies of water) in order to understand how traditional gender roles are constructed through such metaphors in the movie The Yacht Isabel Arrived This Afternoon. Lakoff and Johnson's Conceptual Metaphor Theory (1980) is applied, in particular the concepts of structural and ontological metaphors, as well as the notions of discursive power (van Dijk, 2004) and ideology (van Dijk, 2008). The analysis shows that structural and ontological metaphors throughout the film portray the man as the captain, the protector, and the woman's victim. On the other hand, metaphors representing the woman are the sea, the yacht and the shipwreck. The conclusion is that a feedback process contributes to the dissemination and perpetuation of ideologies of gender roles. The concept of «linguistic obedience» (Komska, 
Moyd \& Gramling, 2019) is key to explain the linguistic behavior of the characters in the film.

Key words: Yacht Isabel, Venezuelan cinema, metaphors, discursive power, gender roles, linguistic obedience.

\section{INTRODUCCIÓN}

La película La balandra Isabel llegó esta tarde (1950) ${ }^{1}$, una coproducción venezolano-argentina de gran trascendencia, ha recibido escasa atención por parte de la crítica no solo cinematográfica, sino también literaria y lingüística. La cinta, de 90 minutos de duración, fue dirigida por el argentino Carlos Hugo Christensen, con guion de Carlos Hugo Christensen y del venezolano Aquiles Nazoa. La pieza está basada en el cuento homónimo de Guillermo Meneses, obra sobre la cual se han llevado a cabo la mayoría de los trabajos de crítica (Cf. Aponte y Baptista, 2011; Lasarte, 1989; Peña, 2000; Sánchez Vega, 2010; Vale, s/f). También se ha estudiado la cinta desde el punto de vista técnico y de la comunicación cinematografía (Cf. Aguilar y Ortiz, 2012; Colmenares España, 2014; Toledo Cruz, 2015; Soffer, 2016). Sin embargo, es poco lo que se ha hecho sobre el discurso en la película. Por lo tanto, este trabajo pretende ser un aporte al acervo de los estudios culturales y lingüísticos basados en la obra cinematográfica venezolana y latinoamericana de la primera mitad del siglo XX.

La balandra... contó con una constelación de grandes estrellas nacionales e internacionales del momento. Los protagonistas fueron el mexicano Arturo de Córdova, como Segundo Mendoza y la argentina Virginia Luque, como Esperanza. Los principales actores de reparto fueron los venezolanos América Barrios, como Isabel, la esposa de Segundo Mendoza, Néstor Zavarce como Juan, hijo de la pareja, y Tomás Henríquez, como el brujo Bocú. Además, se contó con la participación estelar de la argentina Juana Sujo como la loca María. Aguilar y Ortiz (2012) señalan que el proyecto de filmar este relato fue llevado a cabo por Luis Guillermo Villegas Blanco y su empresa Bolívar Films, de Venezuela. La película fue galardonada en el Festival de Cannes (1951) por Mejor Fotografía (J. M. Beltrán) y fue nominada al Gran Premio del Festival. Fue proyectada en el mundo entero, bajo los siguientes títulos: Mariposas negras y Barrio de perdición (México); La caravelle Isabel partira ce soir (Bélgica); L'escale du désir (Francia); L'amante creola (Italia); Frestande hamn (Suecia); Esperantza (Grecia) (Cf. Aguilar y Ortiz, 2012). De ahí que el filme puede ser visto como una de las más grandes producciones cinematográficas venezolanas y latinoamericanas.

Este estudio pretende proporcionar una mirada al discurso fílmico de la primera mitad del siglo XX, entre otras razones porque a través de las películas «se puede conversar desde las diferencias dialectales entre los hispanohablantes, hasta las diferentes tendencias que abarca la Iglesia católica en América Latina, pasando por estilos educativos, relaciones familiares, moral sexual, el narcotráfico y el lenguaje corporal» (Cristoffanini, 2005: 79). Asimismo, Reyes López (2014) expresa que el cine es, ciertamente, de relevancia para fines de investigación del lenguaje verbal. El autor considera que lo que se dice y se hace a través de las palabras en las interacciones representadas en este medio son una herramienta poderosa para el estudio de, en su caso, la cortesía verbal. Sin embargo, me atrevo a asegurar que las películas son fuente

\footnotetext{
${ }^{1}$ No es consistente la fecha con la que se cita la película. Autores como Colmenares España (2014) la ubican en 1949, pero es posible que esté incluyendo la fecha en que iniciaron las filmaciones, que según el artículo de Velázquez (1949), citado más adelante, comenzaron en 1949.
} 
interminable de datos a todos los niveles del habla, y ayudan a desentrañar patrones cognitivos que se manifiestan a través del uso de la lengua.

La manera en la que los investigadores se aproximan al estudio de las metáforas en los medios audiovisuales es sumamente variada, y sus aportes, de gran valor. Algunos de los análisis centrados en la obra cinematográfica se basan, en muchos casos, en la multiplicidad de aspectos y la no literalidad que presenta lo que se ha denominado la metáfora fílmica (film metaphor en inglés) (Cf. Carroll, 1996) pictórica (pictoral metaphor en inglés) ( $C f$. Schilperoord, 2018), la metáfora cinemática (cinematic metaphor en inglés) (Cf. Bateman y Wildfeuer, 2014; Müller y Kappelhoff, 2018) y la metáfora multimodal ${ }^{2}$ y visual (multimodal metaphor y visual metaphor en inglés) ( $C f$. Forceville, 2015; Šorm y Steen, 2018, entre otros). Este tipo de análisis de la metáfora en el cine integra aportes interdisciplinares, así como varios preceptos y tradiciones teóricas desde diversos ángulos del análisis académico del discurso (Müller y Kappelhoff, 2018). En el caso del cine, la actuación, los gestos, la sucesión de imágenes y los diálogos son elementos que colaboran en la creación de la metáfora fílmica. Según Forceville (2015), las películas expresan significados a través de imágenes en movimiento, sonido, música y discurso hablado, lo que las convierte en un medio multimodal por excelencia ${ }^{3}$.

Tales aproximaciones a las metáforas en el contexto cinematográfico son relativamente recientes, por lo que los autores difieren a la hora de definirlas y clasificarlas. Algunos investigadores aseguran que las metáforas fílmicas en sí no existen, sino que hay películas que pueden provocar estados mentales metafóricos en los espectadores; en otras palabras, invitan a la metaforicidad (Schilperoord, 2018). Otros, como Müller y Kappelhoff (2018) afirman incluso que la metáfora cinemática difiere de la multimodal ya que la noción de multimodalidad es limitada a la hora de aplicarla a los medios audiovisuales. Para los autores, las imágenes en movimiento estructuran el proceso de observación del filme como un modo específico de percepción y es de ahí que derivan las metáforas cinemáticas: «[...] las imágenes de un filme no se componen de diferentes modalidades. Como imágenes en movimiento constituyen un modo sui generis» (p. 2, mi traducción, énfasis propio).

El enfoque a la metáfora en el contexto fílmico es tanto interesante como complejo $\mathrm{y}$, en algunos casos, se adentra en aspectos técnicos (movimientos de cámara, acercamientos, sonido, secuencia de imágenes, edición, etc.) que no han sido considerados a profundidad en la realización de este trabajo. Si bien este estudio está basado en una obra cinematográfica, su objetivo se limita a presentar un análisis lingüístico centrado en las metáforas conceptuales verbales que tienen EL MAR (u otras masas de agua) como dominio fuente, para desentrañar su papel en la construcción de los roles tradicionales de género. Análisis de este tipo resultan también de utilidad ya que, según lo afirmado por Lakoff y Johnson (1980) es válido usar expresiones lingüísticas metafóricas para estudiar y entender la naturaleza metafórica de la actividad humana.

Comenzaré por ofrecer una contextualización escénica de la obra, para luego elaborar sobre el aspecto teórico de la metáfora, el poder discursivo y la noción de

\footnotetext{
${ }^{2}$ El análisis de la metáfora multimodal no es exclusivo del cine, también se extiende a las noticias televisivas, campañas publicitarias, caricaturas, videos musicales, videojuegos etc.

${ }^{3}$ Por la forma en que la metáfora se manifiesta en las películas, Forceville (2015) recomienda prestar especial atención a la noción de «modo», para la cual no existe una definición general aceptada, pero imágenes visuales, lengua oral, lengua escrita, sonido, música, gestos, tacto, olores y olfacción constituyen «una lista idiosincrática de modos» (p. 20, mi traducción). Por tanto, concluye el investigador, puede hacerse la distinción entre la metáfora monomodal (cuyos dominios fuente y meta se expresan en un solo modo) y la metáfora multimodal (cuyos dominios fuente y meta se representan a través de varios modos).
} 
ideología. Finalmente, a través de un análisis cualitativo, enfocaré los aspectos del habla más resaltantes en el filme dirigido por Carlos Hugo Christensen, con libreto de Aquiles Nazoa.

\subsection{EL CARIBE VENEZOLANO COMO CONTEXTO DE FILMACIÓN}

La trama central de La balandra Isabel llegó esta tarde gira en torno a la vida amorosa de Segundo Mendoza, el capitán de una pequeña embarcación (la balandra) a la que ha decidido nombrar Isabel en honor a su esposa. Su vida transcurre entre dos puertos y dos amores, el de la Isla de Margarita, donde reside con su esposa y su hijo y tiene una vida familiar, en apariencia feliz; y el de la Guaira, donde habita su amante, Esperanza, una prostituta que recurrirá a todos los métodos, incluyendo la magia negra, para retenerlo.

Aguilar y Ortiz (2012) señalan que, en un artículo publicado en enero de 2012 por el periódico venezolano El Nacional, en conmemoración del centenario del nacimiento de Meneses, autor del cuento La balandra Isabel llegó esta tarde, «se rescata la oscuridad, la noche y la miseria como elementos del cuento La balandra... que acabaron formando parte recurrente de la narrativa del autor» (Aguilar y Ortiz, 2012: 3). Estos elementos se ven perfectamente reproducidos también en la película, la cual se desarrolla principalmente en el Barrio Muchinga de La Guaira, en el Estado Vargas, Venezuela. El barrio caribeño fue rehabilitado para imprimir más realismo a la trama. Velázquez (1949), en una entrevista realizada al actor principal, Arturo de Córdova, expresa lo siguiente sobre Muchinga:

Equipos de albañiles, decoradores, electricistas han sido despachados para La Guaira, a objeto de reconstruir el burdel donde transcurre gran parte de las escenas de La balandra Isabel llegó esta tarde. El recién clausurado barrio de Muchinga-centro de la escoria y la prostitución en el litoral- ha sido objeto de nuevas incursiones, pero esta vez en plan artístico. Se han abierto varias de sus casas para incorporarlas al cine [...]. Ya se han comenzado a tomar algunos exteriores, y el propio Arturo de Córdova, ha inspeccionado el barrio a fin de entrar dentro del personaje que le toca interpretar [...].

(Velázquez, 1949: 2)

Igualmente, se utilizaron locaciones de Caracas, la Isla de Margarita y la Costa de Barlovento, como también diferentes rasgos de su música, tanto la nativa como la afrovenezolana (Aguilar y Ortiz, 2012).

Un texto puede contribuir a que el espectador construya, antes de ver la película, una imagen melodramática del film. Al llevarse a la gran pantalla el cuento de Meneses con todos estos elementos visuales y auditivos se logra una combinación ideal de exoticidad y misterio. A este respecto, Toledo Cruz (2015: 409) señala que la obra se cimienta sobre «una narrativa con elementos del estilo costumbrista venezolano, que mezcla el erotismo con la magia». En internet puede encontrarse que Los Angeles Conservancy, organización dedicada a la preservación del acervo cultural, describió la cinta como un melodrama de una fotografía fascinante, que resalta los escenarios naturales de Venezuela y una herencia musical afrovenezolana insuperable.

Según Colmenares España (2014: 88), en el anuncio del estreno de gala, a beneficio de la Cruz Roja Venezolana, destacan eslóganes como «iMargarita, la isla de las perlas, pletórica de belleza y de paz!» y «¡Barlovento con todo su misterio de tierra virgen!», los cuales contienen metáforas más que reveladoras acerca de la visión de la tierra como mujer exótica o virginal, bellísima y sumisa. El texto del aviso de prensa publicado el día anterior al estreno de La balandra ... dice «Los hombres del mar están 
llenos de pasiones...! [sic] Un amor en cada puerto... El verdadero triunfa siempre...! [sic] Tempestad en el mar y en el alma... y una balandra que trae y lleva amores violentos...! [sic]» (Colmenares España, 2014: 87), preludiando ya el tema de lo marítimo y su relación con la pasión y el carácter de hombres y mujeres.

De ahí que las metáforas en el filme ofrezcan una visión panorámica de la mentalidad del momento.

\section{MARCO TEÓRICO}

En este apartado, se intentará hilar acerca de cómo es la metáfora una ventana al pensamiento popular y la relación que tiene con la construcción de los roles de género.

Aguilar y Ortiz (2012) enfatizan la importancia de crear interrogantes que ayuden a plantear otra mirada sobre la historia del cine; es decir, observar la otra cara del cine, lo que relatan las pequeñas historias. Una manera eficaz de analizar la trama de $L a$ balandra... es a través del estudio de sus metáforas conceptuales verbales. Lakoff y Johnson (1980) explican que los conceptos que gobiernan nuestro accionar del día a día no se reducen solo al intelecto, sino que permean hasta en los detalles más mundanos, esto es «nuestros conceptos estructuran lo que percibimos, cómo nos movemos en el mundo, y cómo nos relacionamos con los demás» (p. 15, mi traducción). Más adelante, los autores señalan que los significados de las metáforas vienen dados por mapas conceptuales metafóricos (también llamados proyecciones metafóricas) que surgen de las correlaciones de nuestras vivencias. La metáfora conceptual es posible gracias a la proyección de elementos de un dominio (fuente) a otro (meta) y se manifiesta a través de su realización lingüística (Kovecses, 2010).

Existen varias definiciones del concepto de metáfora, pero en especial menciono las dos más adecuadas para abordar el lenguaje en la película. La principal es la teoría de la metáfora conceptual de Lakoff y Johnson (1980), para quienes la metáfora consiste en entender y experimentar un hecho según los términos de otro. En otras palabras, las metáforas pueden categorizarse con la fórmula $A$ es $B$ en la que el concepto A es entendido en términos del concepto $B$. En este punto hay que aclarar que no en todas las metáforas se cumple la fórmula ( $A$ es $B$ ), ya que la metáfora puede esconderse en otros elementos, como el verbo, y los analistas del leguaje deben ser capaces de construir la metáfora, a fin de extraer la estructura conceptual subyacente (Forceville, 2015).

Lakoff y Johnson (1980) categorizan las metáforas en tres principales grupos: de orientación, ontológicas y estructurales, siendo estas últimas las que muestran un concepto en términos de otro. Las de orientación tienen que ver con la orientación espacial (p.ej.: arriba-abajo, dentro-fuera, delante-detrás, profundo-superficial, centro-periferia). Estas orientaciones metafóricas no son arbitrarias, se basan en la experiencia física y cultural y varían de cultura a cultura. Las metáforas ontológicas captan la experiencia humana en términos de objetos y sustancias, lo que hace posible seleccionar partes de dicha experiencia y tratarlas como entidades discretas o sustancias de un tipo uniforme. Las metáforas ontológicas pueden referirse a personas, recipientes y sustancias. En el caso del lenguaje de La balandra..., EL MAR es el dominio fuente que da origen a metáforas ontológicas de personificación, recipiente y contenedor.

La segunda definición útil para el presente análisis es la de Hardman (2006), quien denomina este tipo de mecanismos «metáforas generativas», o un abanico de metáforas que todo el mundo entiende porque la imagen de base se atiene a los patrones generales de pensamiento (p. ej.: la guerra, los deportes, la comida). Hardman, Taylor y Wright (2013) explican que todas las metáforas generativas son específicas de cada lengua o cultura en particular, o de un grupo de lenguas con una historia en común. Las autoras 
arguyen que «las palabras toman el lugar del objeto al que se refieren; ese es el proceso de simbolización. Las palabras actúan en el lugar del concepto o lo evocan. El lenguaje metafórico añade otro nivel al proceso referencial» (p. 49, mi traducción). En este caso, EL MAR sería, pues, la metáfora generativa.

Si las metáforas están íntimamente relacionadas con la cultura, el lenguaje empleado en el cine puede y debe tomarse como una reproducción bastante apegada al lenguaje y la cultura dominantes de la vida real, y por ende constituyen una ventana para explorar la mentalidad de una época, en particular las actitudes generalizadas hacia los diversos grupos sociales. Los diálogos de los filmes terminan por mostrar y, en muchos casos, reforzar las ideologías de poder dominantes en una sociedad dada. Ha de recordarse que «El poder discursivo es más bien mental. Es un medio para controlar las mentes de otras personas y así, una vez que controlemos las mentes de otros, también controlamos indirectamente sus acciones futuras» (van Dijk, 2004: 9). Es importante el estudio de este tipo de discurso para lograr entender el modo particular de actuar de ciertos individuos en sociedades en que han sido expuestos a ideologías rígidas sobre roles de género, transmitidas no solo por el boca a boca, sino a través de los grandes medios de «entretenimiento», los cuales, a su vez, fomentan y perpetúan todo tipo de actitudes. El habla de las películas puede lograr los objetivos señalados por van Dijk (2004) con relación al poder discursivo. Estos serían, a saber: manipular, informar mal, educar mal, etc. a otras personas de acuerdo con el interés del emisor del discurso en contra de los más altos intereses de los otros. «De esta manera, una forma para comprender el poder del discurso, tanto como el abuso de este, es comprender exactamente la forma en la que el discurso y sus estructuras afectan las mentes de las personas» (van Dijk, 2004: 9).

A pesar de que proviene de libretos previamente maquinados para construir la historia en pantalla, el discurso cinematográfico es digno de análisis, ya que sostiene un balance sutil entre el realismo y la ficción, las limitaciones del medio y la ilusión de espontaneidad (Rossi, 2011). En los diálogos de La balandra ..., se percibe una actitud paternalista y patriarcal expresada a través de metáforas marinas o relativas al agua. Estos mecanismos del lenguaje servirán para la construcción de las diferencias de género: se observará la categorización de lo femenino como lo débil, lo impuro, lo peligroso, en contraposición con lo masculino como la fuerza, la sabiduría y, paradójicamente, la víctima de la mujer. Entre ellos dos, una sustancia líquida, a veces humanizada (principalmente el mar, pero también otras masas de agua) actúa como ente que gobierna las vidas de mujeres y hombres. Es evidente que la mentalidad patriarcal también afecta a otros personajes masculinos que carecen de cierto estatus frente a la figura dominante, bien sea en la escala socioeconómica (incluyendo oficio) o en fuerza física. Ya ha sido comprobado que en las sociedades patriarcales no solo es característica la diferencia de poder entre mujeres y hombres, sino que en esos contextos «se entrecruzan otras variables que hacen que los jóvenes tengan más poder que los ancianos, los adultos más que los niños, los ricos más que los pobres, los universitarios más que los no universitarios, etc.» (Gimeno Reinoso y Barrientos Silva, 2009: 38).

Todo el entramado social en el que destacan diferencias en el ejercicio del poder puede ser explicado por la noción de ideología. Como bien señala van Dijk (2008: 205):

Las ideologías son marcos básicos de cognición social, son compartidas por miembros de grupos sociales, están constituidas por selecciones de valores socioculturales relevantes, y se organizan mediante esquemas ideológicos que representan la autodefinición de un grupo. Además de su función social de sostener los intereses de los grupos, las ideologías tienen la función cognitiva de organizar las representaciones (actitudes, conocimientos) sociales del grupo, y así monitorizar indirectamente las prácticas sociales grupales, y por lo tanto también el texto y el habla de sus miembros. 
Por ser marcos básicos de cognición, las ideologías dan pie a la formación de metáforas que reflejan el pensamiento social ya que, de acuerdo con Pitra y Zamzani (2019), las metáforas se pueden emplear para construir la perspectiva de los hablantes al expresar sus opiniones. Las metáforas son un puente para el análisis de ideologías de todo tipo, tanto de roles de género ( $C f$. Ahmed, 2018; López Maestre, 2019; López Rodríguez, 2009; Ribas y Todolí, 2008), como de políticas públicas e interacción en contextos educativos (Cf. Morales López, 2016; Pitra y Zamzani, 2019), y en el discurso político (Cf. Adrián, 2009; Díaz-Peralta, 2018; Paz, 2014), por mencionar solo algunos trabajos.

\section{METODOLOGÍA}

La metodología empleada para la elaboración de este trabajo sigue, grosso modo, los pasos para ejecutar la investigación cualitativa propuestos por Cáceres (2003: 58); en otras palabras: Selección del objeto de análisis $\rightarrow$ Pre-análisis $\rightarrow$ Definición de las unidades de análisis $\rightarrow$ Elaboración de reglas de análisis $\rightarrow$ Elaboración de códigos $\rightarrow$ Definición de categorías $\rightarrow$ Síntesis final. Digo grosso modo porque, si bien el objeto de análisis y la definición de categorías son delimitables hasta cierto punto, por el mismo el desarrollo de los diálogos en la película, se obtuvieron algunas duplicaciones. Así, es posible encontrar que una metáfora que caracteriza a la mujer, en ocasiones también puede caracterizar al hombre (p.ej.: el navío). Como bien apunta Cáceres (2003: 59), dentro del contexto de trabajo cualitativo de análisis «los indicadores pueden estar definidos de un modo suficientemente flexible como para no obstruir la emergencia de los temas desde el corpus de información seleccionada».

El objeto seleccionado para el estudio fue el filme La balandra Isabel llegó esta tarde. Durante la fase de pre-análisis se observó con detenimiento la película para determinar si a partir de ella podía constituirse un corpus relativamente nutrido de metáforas conceptuales cuyo dominio fuente fuesen el mar y otros cuerpos de agua. Posteriormente, se planteó la definición del siguiente problema: ¿Cómo se construyen los roles de género a través de las metáforas verbales relativas al mar (u otros cuerpos de agua) en una muestra del cine venezolano de la primera mitad del siglo XX? A continuación, se procedió a la recogida de datos, la cual se llevó a cabo observando la película nuevamente, varias veces, hasta extraer el inventario completo de las unidades de análisis, o las metáforas verbales relativas al mar y a otros cuerpos de agua presentes en la película. Acto seguido, se realizó el conteo y la definición de tres categorías: 1) metáforas que caracterizan al hombre; 2) metáforas que caracterizan a la mujer; 3) otras metáforas y metonimias. A lo largo del análisis de tipo cualitativo se esclarece a qué tipo pertenece cada metáfora, bien sea al estructural o al ontológico. A pesar de que se trata de una muestra muy limitada, a continuación se ofrece un pequeño análisis cuantitativo de los datos:

Tabla 1. Metáforas que caracterizan al hombre

\begin{tabular}{|l|c|}
\cline { 2 - 2 } \multicolumn{1}{c|}{} & $\boldsymbol{n}$ \\
\hline EL HOMBRE ES PROTECTOR Y CAPITÁN & 4 \\
\hline EL HOMBRE ES VÍCTIMA & 3 \\
\hline EL HOMBRE ES NAVÍO & 3 \\
\hline Total $\boldsymbol{n}$ & $\mathbf{1 0}$ \\
\hline
\end{tabular}


Tabla 2. Metáforas que caracterizan a la mujer

\begin{tabular}{|l|c|}
\cline { 2 - 2 } \multicolumn{1}{c|}{} & $\boldsymbol{n}$ \\
\hline LA MUJER ES EL MAR & 11 \\
\hline LA MUJER ES NAVIOO & 2 \\
\hline LA MUJER ES NAUFRAGIO & 2 \\
\hline Total $\boldsymbol{n}$ & $\mathbf{1 5}$ \\
\hline
\end{tabular}

Tabla 3. Otras metáforas y metonimias

\begin{tabular}{|l|l|}
\cline { 2 - 2 } \multicolumn{1}{c|}{} & $\boldsymbol{n}$ \\
\hline EL MAR ES ELEMENTO PURIFICADOR & 2 \\
\hline EL MAR ES DOLOR & 1 \\
\hline Metonimia & 1 \\
\hline Total $\boldsymbol{n}$ & $\mathbf{4}$ \\
\hline
\end{tabular}

Tabla 4. Muestra total de metáforas y metonimias de toda la muestra

\begin{tabular}{|l|c|}
\cline { 2 - 2 } \multicolumn{1}{l|}{} & $\boldsymbol{n} \mathbf{( \% )}$ \\
\hline $\begin{array}{l}\text { Metáforas del mar para caracterizar al } \\
\text { hombre }\end{array}$ & $10(34,4)$ \\
\hline $\begin{array}{l}\text { Metáforas del mar para caracterizar a la } \\
\text { mujer }\end{array}$ & $15(51,7)$ \\
\hline $\begin{array}{l}\text { Metáforas del mar como elemento } \\
\text { purificador o dolor }\end{array}$ & $3(10,3)$ \\
\hline Metonimias & $1(3,44)$ \\
\hline Total $\boldsymbol{n} \mathbf{( \% )}$ & $\mathbf{2 9}(\mathbf{1 0 0})$ \\
\hline
\end{tabular}

Figura 1. Distribución de las metáforas en el filme "La balandra Isabel llegó esta tarde"

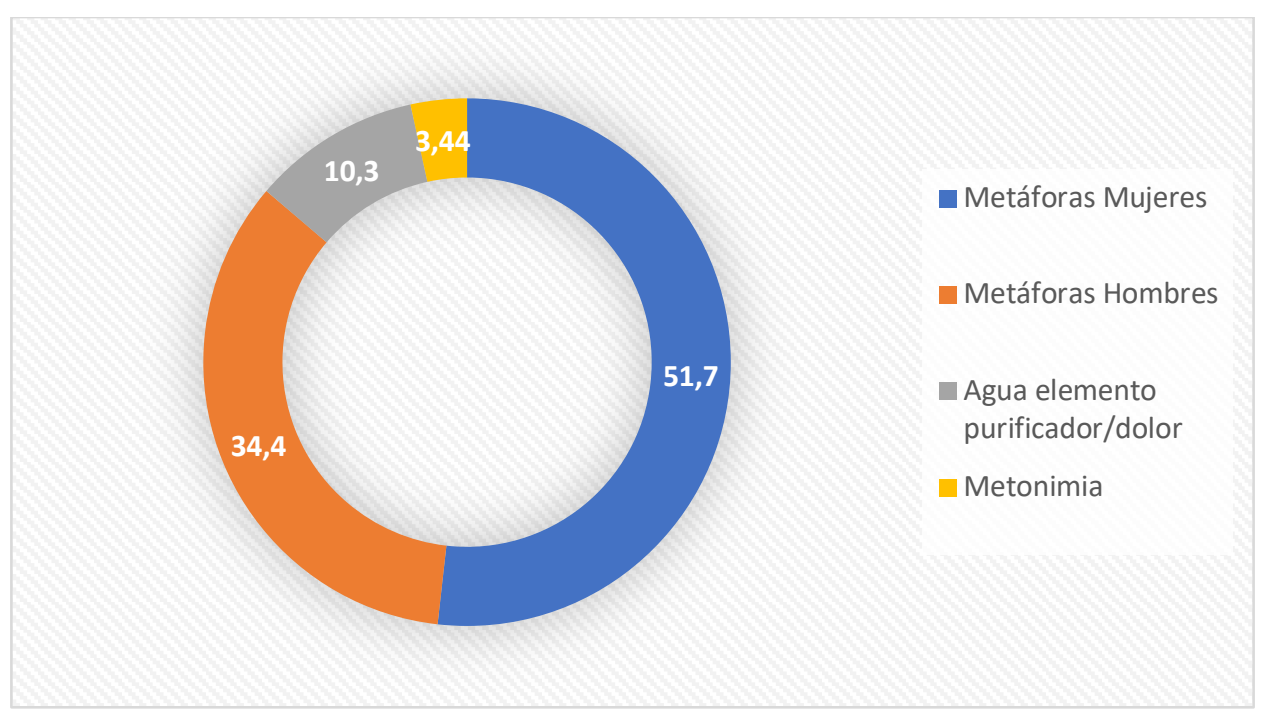


Una vez cuantificados y clasificados los datos se procedió a realizar el análisis cualitativo de lo encontrado. Se ha hecho un intento por diferenciar en dos secciones las metáforas para referirse al hombre y a la mujer. Sin embargo, para respetar la continuidad de la historia, y en otros casos, del fluir del análisis, es posible encontrar solapamientos en ambas secciones.

\section{4. ÁNALISIS CUALITATIVO DE LAS METÁFORAS}

A continuación, se ofrece un análisis lingüístico cualitativo del repertorio de metáforas conceptuales verbales hallado en el filme La balandra Isabel llegó esta tarde. Se divide entre las metáforas que aluden al hombre (incluyendo otras metáforas y metonimias) y las que aluden a la mujer, y dentro de cada apartado se analizan detalladamente. Nótese que cada segmento de diálogo en el que aparece una metáfora lingüística se enumera y se separa del texto para una mejor visualización de los ejemplos que se analizan. En el caso de alegorías, o metáforas continuadas, estas no se fragmentan para no interrumpir el flujo del discurso. Las metáforas identificadas aparecen en cursiva.

\subsection{EL HOMBRE ES CAPITÁN, PROTECTOR Y VÍCTIMA}

Uno de los temas principales de La balandra ... gira en torno a la idea de que EL HOMBRE ES CAPITÁN DE NAVÍO, PADREO PROTECTOR de otros seres que dependen de él. Las estructuras discursivas que, en lo particular, se contextualizan en el campo semántico relativo al mar, denotan fuerte inclinación a mostrar una bipolaridad idealizadora y condescendiente de la figura masculina: por un lado, EL HOMBRE ES EL PADRE PROTECTOR, el EXPERTO CAPITÁN que sabe cómo navegar las aguas turbulentas de la vida y que está en control de su vida y las vidas de los que lo rodean; por el otro, se proyecta al hombre como un individuo virtuoso convertido en VícTIMA por la perfidia de las malas mujeres.

La película inicia con un extranjero a la orilla de un puerto de la Isla de Margarita, en el Estado Nueva Esparta, Venezuela, lanzado monedas a los niños de la zona, que se zambullen en el agua y las atrapan con la boca. En un momento dado, el hijo de Segundo Mendoza, Juan, queda en el fondo del mar sin poder volver a la superficie. Segundo, temiendo que su hijo muera ahogado, se sumerge a salvarlo. Después de rescatarlo y ponerlo a salvo, le quita la moneda, la devuelve al extranjero y lo empuja al agua. Luego de un fuerte regaño a su hijo Juan, este le dice a su padre que lo quiere mucho por regañarlo de ese modo,

(1) Así, pues, como hablan los capitanes viejos, como papá (00:05:55) (Christensen y Nazoa, 1950).

A partir de ahí se establece la hombría de Segundo Mendoza, quien es salvador y protector de los más débiles y cuya sabiduría, aunque sea impartida con cólera, es bien recibida por los demás. ÉL ES EL CAPITÁN, incluso para su propio hijo; él es quien manda tanto en el barco como en la vida familiar. Más adelante, esta idea se ve reforzada por la madre de Juan y esposa de Segundo, Isabel, a quien su hijo le pregunta cómo debe llamar a Segundo cuando trabaje como grumete en su barco, si papá o capitán, a lo que ella responde:

(2) Cuando los hombres trabajan en el mar, el capitán es como un padre para todos (00:09:31) (Christensen y Nazoa, 1950). 
Se entiende entonces que tanto la casa como el barco son una reproducción a menor escala del sistema social piramidal, en el que un hombre, el padre, se halla en la punta, a la cabeza, es el jefe y el guía, y debajo se hallan los demás: mujeres, niños y otros hombres. Todos deben obedecer al capitán quien, como un padre, ordenará la vida de sus subordinados porque en él reside la sabiduría y hay plegarse a sus designios. El personaje de Segundo parece estar al tanto de su propia importancia y predominio en su grupo social, y proyecta orgullo hacia su masculinidad y superioridad al verlas reflejadas en su hijo Juan. El niño los acompaña en los primeros momentos de hacerse a la mar, y cuando se lanza al agua para volver nadando a la orilla, su padre expresa:

(3) Ya es un hombre de mar. Tiene a quién salir (00:15:03) (Christensen y Nazoa, 1950).

La distinción también funciona, como dije, para separar unos hombres de otros, aunque todos puedan estar en dominio de otros más débiles según las circunstancias. El momento del filme que mejor ejemplifica esta jerarquización es el del reencuentro de Segundo con Esperanza: al poco de atracar en el puerto de La Guaira, Segundo se acicala y sube por las calles del Barrio Muchinga. Se dirige al bar El cuerno de la abundancia, donde Esperanza canta, acompañada de las notas de una guitarra, la canción cuya melodía se repetirá a lo largo de toda la película, a veces en voz de otros (como Martinote, el ayudante de Segundo y su hombre de confianza), y con distinta letra, como se verá más adelante en el análisis. Mientras canta, Esperanza sonríe a los hombres que la rodean pero lanza un suspiro de hastío cuando no la ven. Al terminar de cantar, la mujer se toma un trago y al darse cuenta de que Segundo ha llegado a La Guaira, su impulso es salir corriendo a abrazarlo. Sin embargo, se deja ver que ya está en compañía de otro caballero, quien la sujeta fuertemente de la muñeca y le ordena a ella que no se vaya, y a los músicos que sigan tocando. Segundo se acerca al grupo y le dice al hombre que somete a Esperanza: «Suéltela, bachiller, que no se le va a volar» (00:25:24) (Christensen y Nazoa, 1950). Como revancha, «el bachiller» replica «Está equivocado, almirante, yo estoy primero» (00:25:27) (Christensen y Nazoa, 1950). Ante tal afirmación, Segundo responde:

\section{(4) Capitán, para otra ocasión (00:25:31) (Christensen y Nazoa).}

Es significativo el uso de títulos de tratamiento en esta escena: al usar un título académico (bachiller), se expresa cierto desprecio por lo intelectual por parte del hombre que usa la fuerza bruta como modus vivendi y posee otros tipos de inteligencia. Al dirigirse a él como «almirante», el acompañante de Esperanza busca degradar la importancia de Segundo, quien, al llamarse a sí mismo capitán, aclara que su rango es superior, no solo en el mar, sino en la vida de Esperanza y en cuanto a «sus derechos» sobre ella. Para decidir con quién se va Esperanza, apuestan a la mujer en un juego de cartas y Segundo resulta ganador. La relación vertical se muestra claramente: Segundo es el protector, el capitán y, gracias a un juego de azar, el dueño de la mujer; el otro hombre pierde ante Segundo, en este contexto, la posesión de la mujer; Esperanza no puede sino aceptar su destino, fuere cual fuere.

Se hace evidente el papel del cine en la ideologización sobre los roles de género. No ha de olvidarse que el cine puede fungir de «arma ideológica de las clases hegemónicas para consagrar los valores culturales destinados a consolidar su poder» (Bracco, 2017: 14). Esta cinta contribuyó en su momento a la manipulación sobre los roles de género, según los cuales, el hombre, en cualquier circunstancia, debe dominar, y si no puede dominar a otros hombres, debe dominar a los más débiles. Esta actitud no 
siempre es consciente, sino que se manifiesta en acciones que surgen de los patrones cognitivos adquiridos de forma natural a través del lenguaje:

La manera de hablar de hombres y mujeres, en una sociedad refleja los significados que se construyen mutuamente en la interacción social, estos permiten estrechar lazos de convivencia y comprensión entre los miembros de una comunidad, en condiciones igualitarias y armónicas. Pero, buena parte de estos significados son impuestos por la cultura, a través de mecanismos ideológicos que los legitiman y normalizan con unas formas de ser y de pensar disfrazadas de naturalidad y, consecuentemente, terminan asumiéndose como tal por todos los miembros de una colectividad. De esta manera, los significados impuestos se legitiman y expresan en relaciones de poder desiguales e inequitativas, como ocurre en la asignación de roles entre géneros.

(Bustamante Vélez, 2011: 46)

No es de extrañar, entonces, una actitud maniquea hacia el mismo hombre que es padre, protector y experto capitán, pero que también ocupa, cuando llega el momento de atribuir responsabilidades por las acciones cometidas, el papel de víctima del sexo opuesto.

Un personaje secundario, pero que tiene mucho que decir, es la loca María. A su llegada al puerto de La Guaira, Segundo la consigue en las escaleras que dan al bar. En su monólogo, aparentemente sin sentido, María da a entender que a los hombres hay que obedecerlos en todo, y que «no hay hombre malo, mujer porfiada, sí» (00:21:09) (Christensen y Nazoa, 1950). Más tarde, al salir del bar, los amantes se encuentran a María, quien con la siguiente metáfora expresa para sí misma:

(5) Mis gemidos corren como el agua (00:30:09) (Christensen y Nazoa, 1950).

La asociación del líquido con el dolor es obvia. Esta mujer despierta en Esperanza una profunda pena y un enorme miedo de acabar como ella. Esperanza le ofrece un cigarro a María, y esta la insulta a través de la siguiente sentencia:

(6) ¡Tú, me sacaste los ojos y te los tragaste, pa'que yo te vea las entrañas! (00:30:23) (Christensen y Nazoa, 1950).

La metonimia de la parte por el todo que emplea María es reveladora: por un lado, da la idea de que Esperanza es una mujer malvada, que le ha arrancado los ojos a María y la ha vuelto su víctima; y por otro, da a entender que este proceso le ha otorgado a María el poder de la introspección en el alma de la otra mujer: puede verle las entrañas, es decir, el alma, las intenciones. Con ello, se prepara al espectador para lo que se sabrá luego durante el filme: María es la hermana de Bocú, el brujo con el que complota Esperanza para hechizar a Segundo y apartarlo de su familia. Es interesante el hecho de que María haya decidido adjudicarle toda la culpa a Esperanza de tales acciones, haciendo caso omiso de que ella también ha sido prostituta, y terminó enloquecida por llevar esa vida de servidumbre sexual para asegurar la propia sobrevivencia. Nótese que ni la metonimia ni la metáfora tienen relación alguna con el agua o con el mar, sino con la posibilidad de que una mujer penetre en el alma de la otra a través de la ingesta de sus órganos visuales. Se observa el contraste de actitudes hacia lo masculino cuando inmediatamente después de recriminar a Esperanza con tales palabras, María le dice a Segundo: 
(7-8) Pero tú eres el sonoro muchacho de las espumas. Todos los marineros son buenos, porque la mar les ha lavado el corazón (00:30:30) (Christensen y Nazoa, 1950).

La idea de que el mar limpia y purifica se ve reflejada en otras metáforas que se comentan más adelante. El adjetivo «bueno» ${ }^{4}$ refiere a la elevación y la integridad. Incluso para María, una alienada mental, un ser marginado de la sociedad, los hombres están libres de culpa. Es posible que la intención sea poner estas palabras en boca de una mujer que ha perdido la cabeza, para hacer parecer esta categorización menos chocante y menos «anti mujeres».

Sin embargo, a lo largo del filme a María se la muestra como la más perspicaz de los personajes, puesto que conoce a profundidad las intenciones de Esperanza y Bocú y el daño que le intentan hacer a Segundo. Es decir, María está loca porque deambula por las calles y habla sola pero, como los niños y los locos, según la filosofía popular, dice la verdad, o mejor dicho, reproduce el estereotipo de lo que para la época era la verdad: la infidelidad conyugal es natural en el hombre, con el agregado de que la culpa es tanto de la esposa como de la amante; el hombre casado no tiene más remedio que sucumbir ante tales tentaciones para no dejar su hombría en entredicho. En gran parte de la producción literaria $\mathrm{y}$, por extensión, cinematográfica, se observa este patrón de pensamiento. Un ejemplo significativo lo ofrece Nieva de la Paz (2005), en su análisis sobre las obras de Wenceslao Fernández Flórez, en el que la autora concluye que la visión de los hombres casados que se deduce de un conjunto de relatos satíricos estudiados «incide en la universal promiscuidad masculina, en el carácter fundamentalmente frívolo y libidinoso de unos varones prestos a justificar sus infidelidades culpabilizando a las mujeres por ser (y hacer) una cosa o su contraria» (Nieva de la Paz, 2005: 353). Se encuentra además que, desde la perspectiva masculina, la propensión a la infidelidad le surge al hombre por su constitución biológica, gracias a la cual para los hombres es un acto «natural» y para las mujeres es una «desviación» (Nieva de la Paz, 2005: 354).

Se debe distinguir aquí que para que este discurso se reproduzca en el cine, debe existir en dos niveles: el primero, que podría ser el nivel fuente, se halla en la lengua empleada por los hablantes reales, de la cual se nutre el segundo nivel, que podría llamarse el nivel derivado, y el que se analiza en este trabajo. Este nivel derivado se encuentra en el libreto que representan los personajes del filme, y que ha sido previamente planificado por los guionistas que trabajan para la compañía cinematográfica. No por eso puede afirmarse que este discurso (nivel derivado) es falso o afectado. Sobre el texto literario, Zamora (2014: 104) afirma que «(...) no podemos descartar, por juzgarlo de escasa relevancia frente a la investigación de la lengua hablada, el uso de material narrativo procedente de la lengua literaria en los estudios de (...) análisis del discurso». Si la literatura puede verse como un producto de su contexto social (Schmid, 2015), puede decirse lo mismo del texto cinematográfico el cual, en el caso de La balandra ..., traduce y reproduce el lenguaje que expresa el sentir de la gente común, aunque de un modo más metafórico, para hacerlo más dramático, sublimado y atractivo al público.

\subsection{LA MUJER ES EL MAR, EL NAVÍO Y EL NAUFRAGIO}

Al referirse tanto a la mujer como al mar, las metáforas son variadas y hasta contradictorias, y tal como se vio en el análisis cuantitativo, constituyen más de la mitad

\footnotetext{
${ }^{4}$ La primera acepción del DRAE para el adjetivo «bueno» es: De valor positivo, acorde con las cualidades que cabe atribuirle por su naturaleza o destino.
} 
$(52 \%)$ del repertorio total de metáforas en la película. Según el hablante que las emplee, mostrarán un concepto del mar o bien idealizado, positivo y portador de amor, o bien uno que inflige pena y dolor. Las metáforas en este sentido son estructurales y, según estas, LA MUJER ES EL MAR (en sí misma); pero también son ontológicas, ya que convierten al mar como sustancia en un medio que contiene y produce emociones. Lo primero que ha de destacarse en este apartado es que durante toda la película se escucha, bien sea de fondo, o en boca de la misma Esperanza u otros personajes, lo que se llamó en el filme «La canción de Esperanza». La letra de la canción es como sigue:

(9-13) Beso largo de espuma te daría/ Para ser en tus brazos como el mar/ Y hechizarte de bruma y lejanía y ensoñación lunar/ Yo soy tu amor viajero/ Mi capitán/ En mi vela más alta va tu recuerdo/ Y mi voz por la brisa te busca en el mar (00:22:10) (Christensen y Nazoa, 1950).

Los ejemplos 9 a 13, todos dentro de la letra de la canción, conforman una alegoría ontológica al amor y el engaño, ya que está compuesta por varias metáforas relacionadas entre sí y al mar, que aluden al amor imposible y a la desilusión amorosa. En primer lugar, los besos son de espuma, es decir, se diluyen rápidamente, como la compañía de Segundo. Por esto, Esperanza quisiera ser como el mar en los brazos de Segundo, para que ese beso de espuma fuera largo, ya que él es marinero y la mayor parte de su vida transcurre en el agua. El único poder que Esperanza tiene (o cree tener) para retener a Segundo es el de la magia negra, ayudada por el brujo Bocú. Sin embargo, Esperanza les da una connotación romántica y bonita a sus embrujos al llamarlos «hechizo de bruma» y «ensoñación lunar», puesto que la bruma da la idea de una noche tupida, en la que el barco debe desplazarse despacio y con cautela, y la ensoñación lunar evoca el placer y la paz que producen mirar a la luna. A pesar de que ya se ha dicho que la balandra de Segundo se llama Isabel en honor a su esposa, en su mente Esperanza se apropia de ella y del hombre al usar los adjetivos posesivos (en $m i$ vela más alta va tu recuerdo y mi voz/ $m i$ capitán) para referirse a sí misma como el barco en el que navega Segundo, cuyo amor es de ella aunque no esté a su lado (yo soy tu amor viajero). Un amor viajero también sugiere que es la mujer quien espera en tierra hasta que el hombre decida ir hacia ella.

La canción es tema de conversación y produce cierta inquietud durante el filme. Al principio, poco antes de que Segundo partiera a La Guaira, Isabel lo encuentra silbando la tonada y le pregunta por qué le gusta tanto esa canción, que «es hermosa y es triste. Pero no sé, también tiene algo raro» (00:11:07) (Christensen y Nazoa, 1950). Al preguntarle dónde la había aprendido, Segundo miente y le dice:

(14-15) En algún puerto o en el mar tal vez (00:11:16) (Christensen y Nazoa, 1950).

La idea de que la mujer amada es un puerto donde atracar, o el mismo mar, vuelve a verse reflejada en la respuesta de Segundo. Por otro lado, que Isabel sea su balandra propone que la mujer es su contenedor y que resiste a su lado los embates del mar (la vida). La respuesta de Isabel confirma que el mar es un misterio que seduce a los hombres (en particular al suyo) y los vuelve apesadumbrados y melancólicos:

(16) Tal vez en el mar. Tiene toda su seducción y toda su nostalgia (00:11:21) (Christensen y Nazoa, 1950). 
Para tranquilizarla, Segundo le explica a Isabel que todos sus afectos están ahí, a la orilla del mar, «en este pedazo de costa: mi hijo, mi balandra, mi mujer» (00:12:20) (Christensen y Nazoa, 1950). De nuevo se observa el posesivo «mi», esta vez para indicar dominio del hombre sobre los otros.

Con la misma melodía, tanto en boca de Martinote, el segundo hombre al mando en la embarcación de Mendoza, como posteriormente de Esperanza, se insinúa que EL HOMBRE ES UN BARCO ROTO, es el hombre que añora, como navío que aguarda en la noche para hacerse a la mar. En este caso, y al igual que la mujer, EL HOMBRE ES NAVÍO, pero uno que ha sido destrozado por el amor de una mujer:

(17-18) Cuando los barcos rotos y desiertos/ Sueñan bajo la luna con zarpar/ Por las calles nocturnas de los puertos/ Va mi canción al mar (00:16:33) (Christensen y Nazoa, 1950).

Otras metáforas o alusiones al mar se dan cuando Esperanza, queriendo pedirle a Segundo que la ayude a salir de la prostitución, le insiste en que vayan a Playa Escondida, y no a su casa (donde quiere ir Segundo), al justificar que:

(19) Para lo que quiero decirte necesito palabras limpias (...) palabras que allí no encontraría (00:32:12) (Christensen y Nazoa, 1950).

Nuevamente se observa la idea de que el mar tiene la propiedad de lavar y proporcionar pureza. Una vez en la playa, se ve solo a Esperanza sin ropa, presuntamente después de hacer el amor, y ella le pide ayuda a Segundo. Este le dice que sí la ayudará porque ella también tiene derecho a ser una mujer honrada. Acto seguido se escucha otra canción, la de un pescador a la orilla de la playa, que plasma la idea de que LA MUJER ES EL MAR y la arena, portadora de amor pero engañosa, que hace del hombre (EL RÍO) su víctima:

(20-22) Yo me enamoré de noche y la luna me engañó/ La luna no engaña a nadie/ El engañado soy yo/ Yo soy lo mismo que el río y tú lo mismo que el mar/ Tu cuerpo es como la arena/ Donde me tiendo a soñar (00:33:50) (Christensen y Nazoa, 1950).

Con un primer plano del rostro de Esperanza, Segundo, enamorado de ella, también la ve como el mar y surge otra alegoría en la que LA MUJER ES EL MAR:

(23-25) Sí, hay algo de mar en tu cuerpo, de ancho y generoso mar. Es cuando ya tus cabellos se han desmayado en la arena para que yo piense en las espumas (00:34:59) (Christensen y Nazoa, 1950).

El hombre le otorga un sentido más positivo a través del adjetivo «generoso»y dice que piensa en ella como si fuera el mar. Al evocar su cabello sobre la arena se obtiene la imagen de las olas cuando lamen la orilla de la playa. De pronto LA MUJER ES LA NATURALEZA y su cuerpo se confunde con ella a través de imágenes del mar. Por otro lado, no ha de olvidarse que, a pesar de lo mucho que se le idealice, la naturaleza también puede ser una fuerza terrible frente a la cual el ser humano, en particular el hombre en este caso, está totalmente indefenso. En trabajos sobre metáforas en otras lenguas, se observa el uso del concepto del agua para caracterizar a la mujer. Por ejemplo, Nie y Chen (2008) han hallado que, en chino, una mujer promiscua es vista en términos del agua 
porque no tiene un hogar fijo, fluye libre y sin culpas, no tiene forma propia y toma la forma de cualquier recipiente en el que se encuentre.

Esperanza se ha dormido, y comienza Segundo a hablar de su sueño para caracterizar esta acción de la mujer como la entrada del mar en la costa:

(26) Un sueño tranquilo de bahía (00:35:18) (Christensen y Nazoa, 1950).

Continúa el marinero diciendo:

(27-28) Y entonces es el tiempo de mirarte despacio... hasta dormirse a tu lado, como se duermen en los puertos las balandras que han terminado el viaje (00:35:21) (Christensen y Nazoa, 1950).

EL HOMBRE ES UN BARCO que navega y su destino final es el puerto, la mujer. En efecto, las últimas palabras de Segundo esa noche fueron «Me quedaré contigo para siempre, Esperanza» (00:35:44) (Christensen y Nazoa, 1950). Sin embargo, a los tres días, Segundo rompe su promesa y se marcha. Es ahí cuando Esperanza va a buscar a Bocú para preparar el hechizo. Esperanza le jura a Bocú que le agradecerá por siempre si Segundo regresa y se queda a su lado. A dos días de navegación se da a entender que Segundo está totalmente embrujado y así, tal como su embarcación sufre un naufragio, víctima de la naturaleza, ÉL ES LA víCTIMA del embrujo que le ha hecho la mujer. Como dice Martinote:

(29) [ella] lo tiene como endemoniado (00:54:28) (Christensen y Nazoa, 1950).

Al volver a su casa en Margarita, su esposa se da cuenta de que Segundo tiene una amante, pero se reconcilian y ella le pide que regrese a La Guaira, y cumpla el sueño de su hijo Juan de ser su grumete. Mientras tanto, Esperanza sigue reuniéndose con Bocú, suministrándole dinero y favores sexuales. Luego de un desafortunado encuentro entre Juan, Segundo y Esperanza, esta última droga a Segundo en el bar para fugarse a la choza de Bocú, presuntamente para «agradecerle» que el hechizo tuviera éxito. La treta de la mujer tiene un final trágico para Esperanza y Bocú: después de darle una paliza al brujo, Segundo decide volver a su balandra y zarpar de vuelta a Margarita con su hijo y su tripulación.

\section{CONCLUSIÓN}

La muestra de metáforas marinas o relativas al agua y a la naturaleza observada en la película La balandra Isabel llegó esta tarde plantea una polarización del discurso para categorizar los roles tradicionales de hombre y mujer. Por un lado, las metáforas estructurales y ontológicas ponen de manifiesto una ideología sobre los que deberían ser los roles «correctos» de género que, para la época, retratan al hombre como el capitán, el protector y la víctima de la mujer. Por su parte, las metáforas con las que se representa a la mujer son las del mar, el navío y el naufragio, por lo terrible de sus acciones y de su carácter voluble e intrínsicamente extraviado. Son tres imágenes ontológicas que se complementan y oponen entre sí. Por un lado, el mar puede ser calmo, apacible y proporcionar sustento y placer al hombre. Nie y Chen (2008) arguyen que la metáfora del agua para aludir a la mujer se debe a que ambas son suaves y el vínculo entre ellas es que esta suavidad del agua es como la suavidad y la fragilidad de la mujer. Por otro lado, el que Segundo, el capitán que protege y guía a los demás a su cargo, incluyendo a su 
mujer, su hijo y los otros hombres de su tripulación, sea víctima de Esperanza, como si esta fuera un desastre natural, una tormenta en el mar que lo hace naufragar, muestra a la mujer como una fuerza también maligna y perjudicial para su vida, tan poderosa como lo puede ser el mar. Ya ha sido probado antes que algunas metáforas sirven para afirmar que las mujeres son problemáticas, porque su belleza es equiparable a aguas turbulentas y a los poderes destructores del agua (Nie y Chen, 2008: 509).

Según Kozloff (2000: 33, mi traducción), las primeras preguntas que alguien debe hacerse al analizar un segmento de un diálogo de cualquier filme son «ipor qué se dicen estas líneas? ¿cuál es su propósito en el texto global?». Si bien Kozloff aclara que no busca con estas preguntas adivinar las intenciones de los guionistas y del director, advierte que, ciertamente, las ideas conscientes de los cineastas y los efectos finales del diálogo confluyen en gran medida. Tampoco es la finalidad del presente artículo culpabilizar o satanizar a libretistas y cineastas, ya que después de todo, estos responden a los intereses monetarios de los grandes estudios. Lo que sí busco resaltar es que la retroalimentación entre los dos niveles, que denominé fuente y derivado, es obvia; de no ser así, ¿cómo podría reproducirse en el cine la ideología sobre los roles de género si no estuviera también arraigada en la mente de los hablantes que son, a su vez, el público consumidor del producto fílmico?

El cine y otros medios de comunicación son ideales para la diseminación de ideologías, en particular sobre los roles de género. Sin embargo, a todas luces, el ciudadano común también contribuye, consciente o inconscientemente, a la reproducción de un discurso que perpetúa dichas ideologías. A mujeres y a hombres se les inculca, a través del lenguaje, cierto conjunto de normas sociales que no siempre van en pro de sí mismos como individuos. Aunque salirse de estas normas pueda tener consecuencias beneficiosas para ellos y los que están alrededor, también puede traer como resultado la exclusión y hasta el repudio del círculo social inmediato (no en valde existen rebeldes, activistas y luchadores sociales que han sido vilipendiados y hasta han perdido la vida por defender lo que es justo). Este proceso está estrictamente ligado a lo que Komska, Moyd y Gramling (2019:2) llaman «obediencia lingüística». Los autores señalan que los obedientes «reproducen paradigmas coercitivos de pensamiento, sentimientos e identidad, reciclando el lenguaje de sus opresores y de épocas pasadas a pesar de que saben lo que hacen» (Komska, Moyd y Gramling, 2019: 3, mi traducción). Esta noción sugiere que, a menudo, los hablantes emplean la lengua en contra de sus propios intereses buscando no perturbar el statu quo. Las palabras de la loca María en contra de Esperanza y para alabar a Segundo son un ejemplo de obediencia lingüística.

Komska, Moyd y Gramling (2019) intentan explicar los patrones de obediencia lingüística pero no es tan sencillo. Por un lado, justificar la obediencia con la imagen de una falsa conciencia es una idea, sin duda, poderosa y satisfactoria, pero les resulta muy simplista oponer la visión crítica de los expertos contra la del ciudadano común, el cual parece atrapado en un engaño que hace las veces de una rueda de hámster. Estos autores aducen que, si bien a los expertos se les atribuye tener una claridad articulada y transformadora en cuanto al tema, es posible que esta ecuación binaria se venga abajo si, en gran parte de los casos, dichos expertos solo se centran en un número limitado de prácticas de desobediencia lingüística en sus estudios. En definitiva, tanto los expertos como los usuarios regulares de la lengua son todos humanos y es imposible escapar a convenciones e ideologías tan arraigadas en la mente de unos y otros sin hacer un esfuerzo deliberado.

La presente ha sido solo una aproximación muy general al discurso cinematográfico en Venezuela, teniendo como muestra La balandra Isabel llegó esta tarde, para poner de relieve el abanico de metáforas conceptuales con EL MAR como 
dominio fuente que reproducen y perpetúan la ideología sobre los roles de género desde principios del siglo pasado. Finalmente, y según mis apreciaciones, tiene razón Soffer (2016) al argüir en que en nuestros días muchas de las premisas del cine de mediados del siglo XX siguen en vigencia. La autora afirma que tanto en el melodrama latinoamericano, como en el cine negro:

[...] el principal temor es el miedo a la mujer masculinizada; a la mujer con control y poder. A los hombres les atemoriza que esta les arrebate su posición fuerte y dominante en la sociedad; y a las mujeres les da miedo comportarse así porque piensan que eso trae malas consecuencias.

(Soffer, 2016: 136)

El comportamiento lingüístico de los personajes del filme La balandra Isabel llegó esta tarde revela este miedo a salirse de los cánones de la masculinidad y la femineidad.

Investigaciones futuras podrían centrarse en una comparación entre el cine venezolano de la primera mitad del siglo pasado con filmes de la primera mitad del presente siglo, para determinar si continúa empleándose la metáfora en la perpetuación de dichas ideologías.

\section{REFERENCIAS BIBLIOGRÁFICAS}

Adrián, T. 2009. «La metaforización en el discurso político venezolano: Rómulo Betancourt y Hugo Chávez». (Tesis inédita). Universidad Pedagógica Experimental Libertador. Instituto Pedagógico de Caracas.

Aguilar, E. y M. Ortiz. 2012. «La balandra Isabel llegó esta tarde. Crónicas de un viaje: del éxito al olvido» (Trabajo de investigación inédito). Universidad de Buenos Aires. https://hclauba.files.wordpress.com/2009/02/la-balandra-isabel-1legc3b3esta-tarde.pdf

Ahmed, U. 2018. «Metaphor in the construction of gender in media discourse: analysis of metaphors used to describe women in Nigerian newspapers». International Journal of Gender and Women's Studies, 6 (1): 88-99.

Aponte, J. y C. Baptista. 2011. «'La balandra Isabel llegó esta tarde' de Guillermo Meneses como promoción de la literatura venezolana» (Manuscrito inédito). Colegio privado Juan de Dios Andrade, Trujillo, Venezuela.

Bateman, J. A., y J. Wildfeuer. 2014. «A multimodal discourse theory of visual narrative». Journal of Pragmatics, 74: 180-208.

Bracco, C. 2017. «La construcción femenina en los albores del cine egipcio». Imagofagia, 15: $1-15$.

Bustamante Vélez, L. 2011. «Relaciones de poder y dominación en el comercial de televisión 'Snickers: cómete el mundo'». Cuadernos de Lingüistica Hispánica, 18: 43-53.

Cáceres, P. 2003. «Análisis cualitativo de contenido: una alternativa metodológica alcanzable». Psicoperspectivas. Individuo y Sociedad, 2 (1): 53-82.

Carroll, N. 1996. "A note on film metaphor». Journal of pragmatics, 26 (6): 809-822.

Christensen, C.H. (Director) y Nazoa, A. (Escritor). 1950. La balandra Isabel llegó esta tarde. [Película]. Venezuela/Argentina. Bolívar Films. https://www.youtube.com/watch?v=Lb3GDA_2sII\&t=3042s

Colmenares España, M. G. 2014. «El paratexto y la construcción de la imagen genérica en los largometrajes de Bolívar Films (Venezuela, 1949-1955)». X Jornadas de 
Investigación Humanística y Educativa Diálogo entre Humanistas en Época de cambio, Disciplinas y discursos:

https://www.academia.edu/8452206/El_paratexto_y_la_construcci\%C3\%B3n_d e_la_imagen_gen\%C3\%A9rica_en_los_largometrajes_de_Bol\%C3\%ADvar_Fil ms_Venezuela_1949-1955

Cristoffanini, P. 2005. «Estereotipos y mitos: La representación de los ‘latinos' en el cine norteamericano». Sociedad y Discurso, 7: 1-23.

Díaz-Peralta, M. 2018. «Metaphor and ideology: conceptual structure and conceptual content in Spanish political discourse». Discourse \& Communication, 12 (2): $128-148$.

Forceville, C. 2015. "Visual and multimodal metaphor in film: Charting the field». En Embodied Metaphors in Film, Television, and Video Games, ed. Fahlenbrach, K. Routledge, pp. 31-46.

Gimeno Reinoso, B. y V. Barrientos Silva. 2009. «Violencia de género versus violencia doméstica: la importancia de la especificidad». Revista Venezolana de la Mujer, 14 (32): 27-42

Hardman, M. J. 2006. «Question about metaphors». Comunicación Personal por Correo$e(19-03-2006)$.

Hardman, M. J., A. Taylor y C. Wright. 2013. Making the invisible visible: Gender in language: iUniverse. Bloomington.

Kovecses, Z. 2010. Metaphor: A Practical Introduction. Oxford University Press.

Komska, Y., M. Moyd y D. Gramling, eds. 2019. «Introduction: obeying and disobeying». En Linguistic Disobedience. Restoring Power to Civic Language. Palgrave Macmillan.

Kozloff, S. 2000. Overhearing Film Dialogue. Berkeley: University of California Press.

Lakoff, G. y M. Johnson. 1980. Metaphors We Live By. Chicago: University of Chicago Press.

Lasarte, F. 1989. «Guillermo Meneses: hacia una caracterización de su narrativa». Voz y Escritura. Revista de Estudios Literarios, 2 (3): 65-91.

López Maestre, M. D. 2019. «Estudio de las metáforas bélicas para conceptualizar el embellecimiento desde la perspectiva de género: las guerras por la belleza». Culture, Language \& Representation/Cultura, Lenguaje y Representación, 21: 71-91.

López Rodríguez, I. 2009. "Of women, bitches, chickens and vixens: Animal metaphors for women in English and Spanish». Culture, Language \& Representation/Cultura, Lenguaje y Representación, 7: 77-100.

Los Angeles Conservancy. Cinema 2007: http://cinematreasures.org/blog/2007/4/13/another-lrs-in-los-angeles

Morales López, E. 2016. «Metáforas para el cambio social». Discurso \& Sociedad, 10 (4): 781-807.

Müller, C., y H. Kappelhoff. 2018. Cinematic metaphor: experience-affectivitytemporality (Vol. 4). Walter de Gruyter GmbH \& Co KG.

Nie, Y. y R. Chen. 2008. «Water metaphors and metonymies in Chinese: a semantic network». Pragmatics \& Cognition, 16 (3): 492-516.

Nieva de La Paz, P. 2005. «Imágenes de mujer en la narrativa de Wenceslao Fernández Flórez. (Una contribución a la definición ideológica del escritor)». Anales de la Literatura Española Contemporánea, 30 (1/2): 345-369.

Paz, Y. 2014. «El Presidente está enfermo ¿Qué tendrá el Presidente?: La enfermedad y sus metáforas en el discurso de Hugo Chávez Frías». Discurso \& Sociedad, 8 (2): 299. 
Peña, E. G. 2000. «'La balandra Isabel llegó esta tarde’, problemas de recepción de un discurso literario con función de revaloración estética». Letras, 61: 133-150.

Pitra A., y Z. Zamzani. 2019. «Ideology Representation in the Interaction of Teaching and Learning between Lecturers and Students of Economic Education Department of Jenderal Soedirman University». En International Conference on Interdisciplinary Language, Literature and Education (ICILLE 2018). Atlantis Press.

Real Academia Española. 2014. Diccionario de la Lengua Española (DRAE) (23.aed.): https://dle.rae.es/?id=6EawoZ6

Reyes López, M. 2014. «Las estrategias corteses en la realización del acto del cumplido: un análisis a partir de diálogos cinematográficos». Estudios de Lingüística Aplicada, 32 (59): 9-37.

Ribas, M. and Todolí, J. 2008. «La metáfora de la mujer objeto y su reiteración en la publicidad». Discurso y Sociedad, 2 (1): 153-169.

Rossi, F. 2011. «Discourse analysis of film dialogues: Italian comedy between linguistic realism and pragmatic non-realism». En Telecinematic Discourse: Approaches to the Language of Films and Television Series. Piazza, R., Bednarek, M. y Rossi, F., eds. Amsterdam: John Benjamins Publishing Company, pp. 21-46.

Sánchez Vega, R. 2010. «La reescritura como centro de relaciones en cinco relatos venezolanos». Literatura: Teoría, Historia, Crítica, 12: 183-204.

Schilperoord, J. 2018. «Ways with pictures: visual incongruities and metaphor». En Visual Metaphor: Structure and Process. Steen, G., ed. Amsterdam: John Benjamins Publishing Company, pp. 11-46

Schmid, N. J. 2015. «Una niña decente...¿ e inocente?: La intersección de clase y raza en Ana Isabel, una niña decente de Antonia Palacios». Scholarly Horizons: University of Minnesota, Morris Undergraduate Journal, 2 (2): 1-26.

Soffer, A. 2016. «La femme fatale y el arquetipo de la villana: estudio comparativo mediante el personaje de Esperanza en La balandra Isabel llegó esta tarde (1950)» (Tesis inédita). Universidad Católica Andrés Bello, Caracas, Venezuela.

Šorm, E., y G. Steen, 2018. VISMIP: Towards a method for visual metaphor Identification. En Visual Metaphor: Structure and Process. Steen, G., ed.

Amsterdam: John Benjamins Publishing Company, pp. 47-88.

Toledo Cruz, O. 2015. «El cine latinoamericano y sus retratos de la vecindad y el barrio». Razón y Palabra, 19 (90): 405-419.

Vale, A. S/F. «Una aproximación a 'La mano junto al muro’. (Manuscrito inédito). Núcleo universitario Rafael Rangel, Universidad de Los Andes, Venezuela: http://www.saber.ula.ve/bitstream/123456789/26813/1/articulo2.pdf

van Dijk, T. 2004. «Discurso y dominación». Grandes Conferencias en la Facultad de Ciencias Humanas, 4: 5-28.

—. 2008. «Semántica del discurso e ideología». Discurso \& Sociedad, 2 (1): 201-261.

Velázquez, R. J. 1949. «Cine y teatro». Red Venezolana de Comunicación y Cultura Sala Virtual de Investigación Ramón José Velásquez: http://cic1.ucab.edu.ve/cic/php/buscar_1reg.php?\&base=rjv\&cipar=rjv.par\&Mfn $=155$

Zamora, F. J. 2014. «Actividades de imagen en textos narrativos (ficción y no ficción)». Sociocultural Pragmatics, 2 (1): 76-115. 